\title{
Pisara mı Alpkara mı? (İsmi Pek Anlaşılmayan XII. Yüzyılın Bir Garip Türk Kumandanı)
}

\author{
Tuncer BAYKARA
}

Prof. Dr., Uşak Üniversitesi, Fen Edebiyat Fakültesi, Tarih Bölümü (Emekli Öğretim Üyesi), Uşak, Türkiye, baykaratuncer@hotmail.com (Sorumlu Yazar/ Corresponding Author)

\begin{tabular}{ll}
\hline Makale Bilgileri & ÖZ \\
\hline Makale Geçmişi & Yeni yetişen bilim insanlarının daha çok Yunanca kökenli onomastik ismini kullandıkları şahıs \\
Geliş: 15.06.2020 & adları bilimi, tarih araştırmalarında son derece büyük bir öneme sahiptir. Şahıs isimlerinin doğru \\
Kabul: 06.09.2020 & okunuşu, pek çok konunun aydınlanmasında ve doğru anlaşılmasında hayati derecede bir yer tutar. \\
Yayın: 25.12.2020 & Türk tarihine yön veren tarihi şahsiyetlerin isimlerinin yanlış okunuş ve telaffuzları genelde Türk \\
Anahtar Kelimeler: & tarihinin özelde ise, Selçuklu tarihinin en büyük meselelerinden biridir. Bu konu ülkemizde enine \\
Denizli/Ladik, & boyuna müstakil bir şekilde ele alınmış değildir. Daha da acı olanı, birinin yaptığı hatayı bir \\
Alpkara, & başkası hiçbir şekilde tahkik etmeden tekrarlamaktadır. Türk isimleri, kaynağını engin Türk \\
Niketas Khonetas, & kültüründen alır. Bu yazımızda konu ettiğimiz Alpkara ismi de kaynağını Türk Alplik kültüründen \\
İsmail Hakkı & almıştır. Ne yazık ki, yanlış bir okumanın masum kurbanı olarak pek farklı şekillerde karşımıza \\
Uzunçarşılı, & çıkmıştır. Bu konuda en önemli kaynağımız zaten Khoniates diye anılan Honazlı Niketas'ın \\
Osman Turan. & Historia adlı eseridir. İsmail Hakkı Uzunçarşılı da bu konuyla meşgul olmuştur. Bu yazımızda \\
& amacımız Denizli tarihinde büyük yeri olan bir Türk komutanı Alpkara'ya "iade-i isim” dolayısıyla \\
& "iade-i itibar"dır.
\end{tabular}

\section{Is He Pisara or Alpkara? (A Strange Turkish Commander of the XIIth Century, Whose Name Is Not Understood)}

\begin{tabular}{|c|c|}
\hline Article Info & ABSTRACT \\
\hline $\begin{array}{l}\text { Article History } \\
\text { Received: } 15.06 .2020 \\
\text { Accepted: } 06.09 .2020 \\
\text { Published: } 25.12 .2020 \\
\text { Keywords: } \\
\text { Denizli/Ladik, } \\
\text { Alpkara, } \\
\text { Niketas Khonetas, } \\
\text { İsmail Hakk1 } \\
\text { Uzunçarş111, } \\
\text { Osman Turan. }\end{array}$ & $\begin{array}{l}\text { The anthroponymy which the newly grew scientists mostly use the Greek name onomastic, is of } \\
\text { great importance in historical research. The correct reading of personal names has a vital place in } \\
\text { the enlightenment and correct understanding of many issues. The misspellings and pronunciations } \\
\text { of the names of historical figures that shape Turkish history are one of the biggest issues of Turkish } \\
\text { history in general and Seljuk history in particular. This issue is not completely discussed in our } \\
\text { country. What is even more painful is that someone repeats his/her mistake without any further } \\
\text { investigation. Turkish names take their source from the profound Turkish culture. The name } \\
\text { Alpkara, which discussed in this article, has taken its source from the Turkish Alpine culture. } \\
\text { Unfortunately, we have come across with this name in many different ways as the innocent victim } \\
\text { of a wrong reading. Our most important resource in this regard is the work of Honaz Niketas } \\
\text { already known as Khoniates, Historia. İsmail Hakk1 Uzunçarş1l has also been busy with this issue. } \\
\text { In this article, our aim is "restoration of honor" for Alpkara, a Turkish commander who has a great } \\
\text { place in Denizli history. }\end{array}$ \\
\hline
\end{tabular}

Atıf/Citation: Baykara, Tuncer. "Pisara mı Alpkara mı? (İsmi Pek Anlaşılmayan XII. Yüzyılın Bir Garip Türk Kumandanı)". Selçuklu Medeniyeti Araştırmalarl Dergisi (SEMA) 5 (Aralı 2020), $136-139$. https://doi.org/10.47702/sematr.2020.9 


\section{GíRiş}

Alp Arslan'ın Malazgirt Zaferi sonrasında sür'atle Anadolu'nun fethine girişen Türkler, Batı Anadolu ve Marmara sahillerine kadar ulaşmışlardı. Bu çerçevede Denizli/Ladik/Laodikeia'ya kadar fethedilmiş olmalı ki, 1119 senesinde Denizli/Ladik/Laodikeia üzerine yürüyen Doğu Roma/Bizans ordusu, bu şehri kuşatıp almış idi. ${ }^{1}$ Bu durumun gelişmesinde şüphesiz I. Haçlı Seferi’nin büyük rolü olmuştu. Zira I. Haçlı Seferi'nden sonra Türkler Batı Anadolu ve Marmara sahillerinde ele geçirdikleri yerlerden çekilmişlerdi.

Bizans kaynakları, şehri savunan Türk kumandanının adını Alpkara olarak vermektedirler. Burada en önemli kaynağımız zaten "Khoniates" diye anılan Honazlı Niketas'ın eseridir. ${ }^{2}$ Dönemi anlatan eserinde şöyle der:

“Imparator, Türklerin Imparator Aleksios'un kendileri ile akdetmiş oldukları anlaşmalara riayet etmeyerek büyük askeri birliklerle Menderes nehri kenarında Phrygia'da bulunan şehirlere taarruz ettiklerini haber ald. Bu sebeple ilkbahar (1119) başlangıcında sefere çıkı onları muhtelif savaşlarda mağlup ettikten sonra Laodikeia şehrini zapt ederek burasını surlarla çevirdi. Şehrin korunması ile görevli Alpikharas'ı yerinden attı ve gerekli diğer düzenlemeleri yaptıktan sonra Istanbul'a döndü."”

İlginç olanı Alpkara üzerine yürüyen Bizans ordusunun öncü birliğine bir Türk'ün kumanda etmesidir: Aksakus/Ak-kuş. Alpkara ismi günümüz tarihçileri arasında çok fazla bilinmez. Hattâ denilebilir ki, Denizli yöresinin tarihçileri dışındakiler için bu adın fazla bir önemi yoktur. Ancak bu olayların geçtiği coğrafyanın insanı olup, 30-40 yıl sonra dünyaya gelen Niketas'ın komşusu şehirde olup bitenleri duyduğu ve oradaki Türk kumandanın adını da kesin olarak doğru tesbit ettiği için bu ismi kabul etmek gerekir.

XX. yüzyılda, Denizli yöresi için Tarih-i Osmani Encümeni Mecmuası'nda bazı çalışmalar vardır. Fakat bunların yanında döneminin tarihçilerinden İsmail Hakkı Uzunçarşılı (1888-1978) bu konuyla meşgul olmuştur. ${ }^{4}$ Gerçi İngiliz arkeolog P.V.Ramsay, Lycus/Çürüksu vadisi adlı antik dönemi esas alan İngilizce araştırmasında Bizans'ın son zamanlarındaki Türk devirlerine de temas eder. Ancak, çoğunlukla Fransızca bilen Osmanlı aydınlarının ellerinde o eser değil, Charles Texier'in "Küçük Asya" diye Türkçe'ye de çevrilen "Asie Mineure" kitabı vardır. Uzunçarşılı ise, o dönemde Maarif Müfettişi de olduğundan yazdıkları taşra aydınları tarafindan daha o yıllarda ilgi görmeye başlar. O’nun kitabelerden söz eden eserinin ilk basımı Osmanlıca, ikinci basımı ise, harf inkılâbından sonra 1929 (Rumi 1347) yılında Devlet Matbaası'nda yapılmıştır.

Buradaki Denizli bölümünü yazarken "görülen eserler" listesinde, ilk adı geçen kitap olan, Zambaur'un Geneoloji 'sine uzun bir süre ulaşamadım. Biraz Fransızca bildiğim için Bizans tarihçisi Lebeau'nun Paris'te 1757'de yayımlanan Histoire du Bas Empire adlı eserinin basılan ciltlerinden istifade ettim. Ama E.R von Zambaur'un (1866-1947) 1927'de Hannover'de basilan Manuel de Genealogie et de Chronologie Pour L'Histoire de L'İslam adlı bir kitabının olduğunu da biliyordum. Zambaur, Alman asıllı olan Avusturyalı bir yazar idi. Kitabını Fransızca kaleme almasına rağmen,

\footnotetext{
${ }^{1}$ Tuncer Baykara, Denizli Tarihi (İstanbul: Fakülteler Matbaası, 1969).

${ }^{2}$ Niketas Khoniates, Historia (Ionnes ve Manuel Komnenos Devirleri), çev. Fikret Işıltan (Ankara: Türk Tarih Kurumu, 1995).

${ }^{3}$ Khoniates, Historia (Ionnes ve Manuel Komnenos Devirleri), 8.

4 İsmail Hakkı Uzunçarşılı, “Afyon Karahisar, Sandıklı, Bolvadin, Çay, İsaklı, Manisa, Birgi, Muğla, Milas, Peçin, Denizli, Isparta, Atabey ve Eğirdir deki Kitabeler ve Sahip, Saruhan, Aydın, Menteşe, İnanç, Hamit Oğulları hakkında malûmat", Anadolu Türk Tarihi Vesikalarından II. Kitap (İstanbul: Devlet Matbaası, 1347/1929).
} 
Uzunçarşı11’nın istifade ettiği kişi Zambaur'un eserini Almanca kabul edip Uzunçarşılı'ya da o şekilde bildirmiş olmalı.

Uzunçarşılı'nın bu eserinden bir müddet sonra "Alpkara” isminin geçtiği iki ayrı çalışmaya rastlanıldı. Bunlardan ilki İslam Ansiklopedisi'ndeki Alaşehir maddesini yazan, yine dönemin akademik alandaki en ünlü Selçuklu tarihçisi sayılan Mükrimin Halil Yinanç (1898-1961)'ın eseri idi. O, Alaşehir'e 1119'da gelen Bizans ordusunun Laodikeia'daki Alpkara üzerine yürüyüp onu geri çekilmeye mecbur ettiğini yazıyordu.

İkinci çalışma ise, yine Selçuklu tarihçisi sayılan Osman Turan'a ait idi. O, 1971'de yayımlanan ve büyük yankılar bulan Selçuklular Zamanında Türkiye 5 adlı eserinde Uzunçarşıllı'nın okuyuşunu kabul etmişti. Turan, eserinde şöyle diyordu:

“Akkuş kumandasında bulunan öncü kuvvetler ile birlikte Alaşehir'den Denizli’ye geçti. Bu bölgenin Selçuklu valisi olan Emir Başara (Picharas) 'yı mağlup ve şehri zaptetti". ${ }^{6}$

Osman Turan'ın dönemin Selçuklu batı sınırı kenarındaki gücün Türk kumandanı, halis bir Türk adı taşıması gerekirken "Başara" gibi bir ismi tercih etmesini biz, Uzunçarşılı'ya bir saygı olarak kabul ediyoruz. Bu zatın özellikle "Beğ" yerine Arapça "Emir" sıfatıyla anılması da dikkat çekicidir. Oysa gerçekte durum hiç de öyle görünmemektedir.

XX. yüzyıl şartları icabı Türk ilmi geleneklerini teessüs zamanı olduğundan olsa gerek rahmetli üstad Uzunçarşıl1, yabancı tetkik eserlerdeki okunuşlarını esas almıştır. Oysa dünyayı az çok takip eden Köprülüzade Mehmed Fuad Beyefendi, çağdaş bilim usullerine uymuştur. Fransızca'nın Türkçe okunuşu Uzunçarşılı'nın eseri boyunca hâkim olmuştur. Laodikeia değil, Laodisa/Laodise'dir. Oysa bu yıllarda asli imlaları ve okunuşlarını F.V Ramsay'ın, çoktan basılmış ve ulaşılabilir olan İngilizce tetkiklerinde bulabilirdi.

Bunları rahmetli üstad Uzunçarşılı'nın, XVIII. yüzyıla ait bir Bizans tarihi tetkik eseri olan Lebeau'daki Fransızca ismi Türkçe okunuşu ile kitabına darcettiği için hatırlattık. Çünkü oradaki Picharas, ancak Pişara okunur; gerçi dönemin diğer bazı Bizans vakanüvis kaynaklarında bu ismin başında bir "al" varsa da, Lebeau onu muhtemelen Arapça'daki isimlerin başına getirilen "al" kabul edip atmış, ikinci yarısını yazmıştır. Burada da bir başka husus dikkati çekiyor. M.Halil Yinanç, kütüphanelerdeki Bizans vakanüvislerin eserlerinin Fransızca çevirilerinin bazılarında bu ismin "Picaras" ve “Alpicaras” yazıldığını özellikle de Niketas'daki kaydını bizim gibi görmüş olmalıdır.

Çaka'da "k" olarak kabul eden Grek alfabesindeki harfi, bir dönem Çaka'da da Çaha şeklinde okuyanlar da olmuştur. Bizans kaynağını dönemin yaygın dili Fransızca'ya çevirenler bu harfi "ch" diye naklediyorlar. Devrin uzmanları, bunu "ş" değil "kh" olarak da kabul ederler. Alpkara'daki asli harfinde de kimi zaman "ch" diye nakledildiğini görüyoruz. Başka dile çevrilirken buradaki "ch" yanlışlıkla "ş" olarak algılanmaması için bazıları bunu "kh" olarak da naklediyorlar. Yakınlarda doktorasını orada yaptığından iyi Fransızca bilen bir dostumuzun XIII. yüzyıldan söz eden bir Batılı tarihçinin yazarın makalesini Türkçe'ye çevirirken genellikle "Chonae" diye yazılan "Honaz"ın adını Türkçe okunuşu gibi "Şonay" olarak çevirip basıldığını dehşetle görmüştüm. Bizim Alpkara'nın "Pişara" olması ona göre daha masum kalıyor.

Pişara'nın nasıl oluştuğunu bilmeyen bazı Türk Tarihçileri ve aydınları, bunu bir gerçek kabul edip buna en yakın Selçuklu dönemi ismini hatırlatıyorlar. Bu da "Beşare" olup, rahmetli Müjgan Cunbur bunu bana bir kongrede sözlü olarak bildirmiş idi. Tabii ben ona sadece "Ben, Mükrimin Halil

\footnotetext{
${ }^{5}$ Osman Turan, Selçuklular Zamanında Türkiye (İstanbul: Turan Neşriyat Yurdu), 1971.

${ }^{6}$ Turan, Selçuklular Zamanında Türkiye, 160.
} 
Yinanç'ın Alpkara olarak kabulüne katıldım.” diye kısa bir cevap vermiştim. Yakınlarda Selçuklular ve Bizans ${ }^{7}$ diye bir kitap yazan eski lisans talebem Yusuf Ayönü’nün kitabında aynı sanıyı görünce hayretlere düştüm. Çünkü bu defa "Başara"nın başına, muhtemelen Osman Turan'a hürmeten bir de "Emir" eklenmişti. ${ }^{8}$ Gerçi Ayönü burada Osman Turan'1 tercih etmişse de, Alpkara’yı da unutmamıştır. Eskilerin "Bey/Beğ" yerine "Emir" demelerini yadırgamayabiliyoruz (Uzunçarşılı, Yinanç ve hatta Turan gibi). Ama kaynak dili olarak Arapça okuyan genç bilginlerde, güzelim Türkçe Beğ/Bey dururken "Emir" demeleri yaygınlaşmak eğilimindedir (Y.Ayönü, M. Kesik gibi).

\section{SONUC}

Şunu kesinlikle bilmeliyiz ki Alpkara, XI-XII. yüzyıllarda Türkistan sahasındaki Türkler'de namlı şahsiyetlerin adıdır. Gözü kara/yiğit Alp gibi derin manaları içerir. Türk'ün ve Türkçe'nin ruhuna uygundur. Wilhelm Barthold, Selçukluların erken devirlerinde rastlanan Alpkara'ya "general" deyip onun askeri özelliğini belirtmiştir.' Oğuz Yabguları neslinden gelen Şahmelik' in hizmetindeki Ali Tegin'in kumandanlarından Alpkara, Selçuk'un torunu Yusuf'u öldürmüşş ${ }^{10}$, birkaç yıl sonra da Çağrı ve Tuğrul Beyler de 1030 yılında Alpkara'yı öldüreceklerdir.

Yeni araştırmalarda ilk Alpkara'ya "Baranî" yani Baran oymağından olduğu söylenmekte, hatta Oğuz Yabguları ile akraba olabileceği de iddia edilmektedir. ${ }^{11}$ Barthold bir başka Alp-kara'dan Alpkara Uran diye söz ediyor $\mathrm{ki}^{12}$, Kıpçaklardan Uran boyunun önderi olup 1182 'den sonra Harezmşahların hizmetine girmişti. Sanıyoruz ki "Alpkara", bundan böyle Pişara'dan bozma Başara'nın yerini alacaktır.

\section{KAYNAKÇA}

Ayönü, Yusuf. Selçuklular ve Bizans. Ankara: Türk Tarih Kurumu, 2. Basım, 2018.

Khoniates, Niketas. Historia (Ionnes ve Manuel Komnenos Devirleri). çev. Fikret Işıltan. Ankara: Türk Tarih Kurumu, 1995.

Barthold, Wilhelm. Turkestan Down to the Mongol Invasion. London: Southern Materials Center, 3. Basim, 1968.

Barthold, Vassiliy Vladimiroviç. Moğol İstilasına Kadar Türkistan. haz. Hakkı Dursun Yıldız. İstanbul: Kervan Yayınları, 1981.

Uzunçarşı1ı, İsmail Hakkı. "Afyon Karahisar, Sandıklı, Bolvadin, Çay, İsaklı, Manisa, Birgi, Muğla, Milas, Peçin, Denizli, Isparta, Atabey ve Eğirdir deki Kitabeler ve Sahip, Saruhan, Aydın, Menteşe, İnanç, Hamit Oğulları hakkında malûmat”. Anadolu Türk Tarihi Vesikalarından II. Kitap. İstanbul: Devlet Matbaas1, 1347/1929.

Turan, Osman. Selçuklular Zamaninda Türkiye. İstanbul: Turan Neşriyat Yurdu, 1971.

Baykara, Tuncer. Denizli Tarihi. İstanbul: Fakülteler Matbaası, 1969.

Ayan, Ergin. "Selçukluların Şâhmelik ile Macerası ve Harezm'i Fethi”. Marmara Türkiyat Araştırmaları Dergisi 1/2 (Sonbahar 2014), 13-38.

\footnotetext{
${ }^{7}$ Yusuf Ayönü, Selçuklular ve Bizans (Ankara: Türk Tarih Kurumu, 2018).

${ }^{8}$ Ayönü, Selçuklular ve Bizans, 114. Bk. Dizin: Alpkara (Emir Başara).

${ }^{9}$ Wilhelm Barthold, Turkestan Down to the Mongol Invasion (London: Southern Materials Center, 1968$), 297$.

${ }^{10}$ Vassiliy Vladimiroviç Barthold, Moğol İstilasına Kadar Türkistan, haz. Hakkı Dursun Yıldız (İstanbul: Kervan Yayınları, 1981), 371.

11 Ergin Ayan, "Selçukluların Şâhmelik ile Macerası ve Harezm’i Fethi”, Marmara Türkiyat Araştırmaları Dergisi 1/2 (Sonbahar 2014), 13-38.

${ }^{12}$ Barthold, Turkestan Down to the Mongol Invasion, 340, 341, 343.
} 